\title{
TRAJETÓRIAS E PROJETOS DE VIDA DOS JOVENS DO MOVIMENTO AGROECOLÓGICO DE ARAPONGA - MG
}

\author{
TRAJECTORIES AND LIFE PROJECTS OF THE YOUTH OF THE AGROECOLOGICAL \\ MOVEMENT OF ARAPONGA - MG
}

Edna Lopes MIRANDA¹, Maria das Dores Saraiva de LORETO², Everton Lazzaretti PICOLOTTO³

Artigo recebido em 11/06/2021, aceito em 17/06/2021, publicado em 25/06/2021.

Palavras-chave: Trajetória; Projetos de Vida; Juventude rural.

Keywords:

Trajectory; Project Life; Rural Youth

\section{RESUMO}

Com o objetivo de analisar as influências do movimento agroecológico nos projetos de vida dos jovens rurais, utilizou-se metodologicamente de questionários, entrevistas e história de vida dos jovens participantes do movimento agroecológico do município de Araponga/MG. Os resultados apontaram que a maioria dos jovens entrevistados encontrou na agricultura familiar um campo fértil para a difusão dos princípios da agroecologia e criou as condições necessárias para que a unidade de produção passasse a ser entendida também como uma unidade de vida. Na medida em que passaram a adotar os princípios e as ações do movimento agroecológico, seus projetos de vida foram orientados não exclusivamente por uma racionalidade econômica, mas igualmente por relações que têm raízes numa condição de vida familiar tradicional, pautada pela sociabilidade. Concluiu-se que, o movimento agroecológico apresentou uma forte influência nos projetos de vida dos jovens rurais, que manifestaram o desejo de permanecerem no meio rural e terem seu próprio negócio.

\section{ABSTRACT}

With the aim of analyzing the influence of agroecological movement in the life projects of rural young people, we methodologically used forms, interviews and background history of young participate in the agroecological movement of Araponga/MG. The results showed that the majority of young people interviewed found in family farming a fertile field for the dissemination of the principles of agroecology and created the necessary conditions for the production unit to also be understood as a unit of life. As they began to adopt the principles and actions of the agroecological movement, their life projects were guided not only by economic rationality, but also by relationships that have roots in a condition of traditional family life, guided by sociability. It is concluded that the agroecological movement had a strong influence on the life projects of rural young people, who expressed the desire to remain in the countryside and have their own business.

\footnotetext{
1 Pós-Doutoranda em Ciências Sociais Aplicadas no Programa de Pós-Graduação em Economia Doméstica pela Universidade Federal de Viçosa. Doutora em extensão Rural, Mestre e Bacharel em Economia Doméstica pela Universidade Federal de Viçosa.

2 Professora Titular do Departamento de Economia Doméstica da Universidade Federal de Viçosa. Doutora em Economia Aplicada, com Pósdoutorado em Família e Meio Ambiente pela University of Guelph-Canadá.

3 Professor do Departamento de Ciências Sociais e dos Programas de Pós-Graduação em Ciências Sociais e em Extensão Rural da Universidade Federal de Santa Maria (UFSM), RS Doutor em Ciências Sociais pela Universidade Federal Rural do Rio de Janeiro (UFRRJ). https://orcid.org/0000-0003-4199-5553.
} 


\section{INTRODUÇÃO}

Este artigo é resultado da dissertação de mestrado "Protagonismo, Participação e Projetos de Vida: movimento dos jovens agroecológicos no munícipio de Araponga-MG", que teve como objetivo analisar o processo de construção, interações e alcance dos movimentos sociais rurais, examinando sua sustentabilidade e as repercussões sobre os projetos de vida dos jovens rurais do município de Araponga, MG. Os estudos sobre a juventude rural vêm ganhando notoriedade ao discustir sobre a complexidade dos elementos que compõem as identidades juvenis, construídas de acordo com o gênero, a condição social e econômica, a cultura, o lugar de origem, dentre outras variáveis.

Dessa forma, as relações sociais se constroem no presente, movidas pelas tradições familiares e locais do passado, bem como por alternativas possíveis ao futuro das gerações e à reprodução do estabelecimento familiar. Estas dinâmicas se interligam e, através delas, emerge um ator social multifacetário que pode ser portador, ao mesmo tempo e paradoxalmente, de um ideal de ruptura e de continuidade do mundo rural (Carneiro, 1999 \& Castro, 2005).

Conforme Carneiro (1998), atualmente torna-se cada vez mais difícil delimitar as fronteiras entre 0 espaço rural e o urbano, devido à aproximação das relações de trabalho e dos modos de vida estabelecida entre eles. É neste "campo de possibilidades", que os jovens rurais alinham seus projetos de vida que podem mudar de acordo com as transformações vivenciadas pelos jovens ao longo desse processo, pois são essencialmente dinâmicos.

Conforme destaca Velho (1999, p.104), o projeto "é permanentemente reelaborado, reorganizando a memória do ator, dando novos sentidos e significados, provocando repercussões na sua identidade". É neste contexto que se aponta para a emergência dos movimentos sociais rurais, como também para a participação e protagonismo juvenil, seja na perspectiva de permanência do jovem no meio rural, seja como necessidade de buscar outros espaços de vida e sociabilidade.

Ao fazer uma análise da juventude rural dentro do movimento social de luta pela terra, Castro (2008, p.27.), mostra o seu modo de ver as mobilizações e organizações construídas pelos jovens rurais como uma reafirmação da identidade. Isto é, o "querer ficar no campo mais que um desejo, é uma luta cotidiana dos jovens e de seus familiares". De acordo com Castro (2009), a juventude rural se apresenta nos espaços de organização dos movimentos sociais, participando e atuando no cotidiano dos espaços rurais, a partir da diversidade e auto-representação, discursos e práticas, para tratar de processos de construção de identidades culturais. Nessa perspectiva, os jovens são membros de uma coletividade relacionando-se com os demais sujeitos em diferentes contextos, assimilando o que é produzido e ao mesmo tempo produzindo.

A diluição das fronteiras materiais e simbólicas entre o meio rural e o urbano faz com que os jovens reelaborem suas identidades sociais, permitindo a convivência no mesmo espaço social de prática e valores, 
isto é, articulando elementos do rural e do urbano (Carneiro, 1999). Ou seja, o jovem enquanto sujeito social produz e reproduz na própria realidade, na relação que estabelece com a natureza e com o lugar que ocupa na produção - sua classe social. É nesta relação que se constrói a subjetividade do sujeito, que auxiliará na compreensão dos processos de construção e significação dos projetos de vida (Melucci, 1997).

As discussões no Brasil acerca da juventude rural despontaram no momento em que ocorreram profundas transformações no campo (por volta da década de 1990), levando à reflexão sobre qual o papel do jovem em um cenário de desigualdades e, sobretudo, para delinear qual é a postura da juventude diante de tais problemas. 0 processo de modernização da agricultura provocou transformações substanciais na estrutura fundiária do país, representadas pela concentração da posse da terra, pela inversão da relação campo-cidade e pelo êxodo rural, resultante da mecanização do campo, com a população migrando para as cidades.

Além disso, o difícil acesso às políticas públicas básicas, como educação, lazer e cultura também têm tido um peso significativo na saída desses jovens para as cidades. Essas transformações trouxeram reflexos diretos na estrutura familiar das pessoas que viviam no campo, onde as condições de trabalho e renda tornaram-se precárias, ocasionando o êxodo rural (Carneiro, 1999 \& Balsadi, 2001). Não se pode negar que os jovens que vivem nas áreas rurais ainda enfrentam outras situações, como o preconceito quanto à sua origem, dificuldades de acesso às novas tecnologias, ao lazer, à cultura e à educação de qualidade.

Considerando as especificidades da agroecologia e a relevância dos jovens, enquanto atores fundamentais nos movimentos sociais rurais, o presente artigo buscou analisar as influências do movimento agroecológico nos projetos de vida dos jovens rurais de Araponga - MG, considerando suas motivações e expectativas futuras. Enfim, busca-se responder aos seguintes questionamentos:

$\mathrm{O}$ que pensam os jovens rurais sobre seu presente e futuro? De que modo os jovens nesse contexto organizam e alinham seus projetos de vida? Como é possível identificá-los e caracterizá-los? No que se assemelham e no que diferem de outros tipos de projetos? Quais são as ações ou estratégias protagonizadas por estes (as) jovens participantes do movimento agroecológico e como isto tem influenciado seus projetos de vida? Essas e outras questões são inquietantes e levam à reflexão sobre o papel da juventude no contexto atual, em especial, o papel da juventude no meio rural brasileiro.

A partir dessas discussões, pretende-se aprofundar sobre a problemática indicada, levando em consideração, sobretudo a relação do movimento agroecológico com a idealização dos projetos de vida destes jovens. 


\section{MARCO TEÓRICO}

\subsection{Conceituando a Juventude Rural}

Os estudos sobre a juventude rural no Brasil têm evidenciando sua inconsistência temporal, cultural e simbólica, devido ao fato da condição juvenil ser uma construção social, cultural e histórica, que emerge sob diferentes categorias empíricas: jovens rurais; jovens agricultores; jovens do interior; jovens do sertão; jovens empreendedores rurais; jovens filhos de agricultores; jovens rurais ribeirinhos; jovens sem-terra e juventude rural (Wheishemer, 2009). Para esse mesmo autor, estas delimitações acabam por ser produzidas a partir de duas dimensões: uma mais relacionada à dimensão geográfica e o local de residência e outra, incorporando a definição de processo de socialização peculiar deste grupo. Já para Alves e Ferreira (2008, p. 245), "a juventude rural representa uma categoria chave não só para a reprodução social do campo como também para a agricultura familiar e não se limita às especificidades de cada grupo" como citado anteriormente por Wheishemer (2009).

Outros trabalhos acadêmicos, como de Castro (2005), Wanderley (2007) e Piancentini (2016), afirmam um lugar comum para a categoria "jovem rural", como aquele que se encontra, na maioria das vezes, num constante paradoxo, entre os projetos pessoais, de constituir outra família, sair da agricultura ou, por outro lado, ficar e assumir um papel protagonista na reprodução da família, perpetuando práticas produtivas, preservando culturas e saberes, enfim, referendando um modo de vida próprio e particular.

Nos estudos de Dayrell (2010), a juventude é considerada como uma categoria de análise "epistemologicamente imprecisa"; por isso, para estes pesquisadores, não se pode falar em uma única juventude, mas sim em juventudes e isso se deve à diversidade de condições sociais, econômicas e culturais que caracterizam os diversos grupos juvenis. Assim, a juventude rural possui peculiaridades e características que os diferencia dos demais grupos juvenis, especialmente dos jovens de áreas urbanas e das grandes cidades. Estas características estão associadas aos estilos de vida, de moda e comportamentos, que atribuem à juventude o papel de propulsora real ou potencial dos processos de transformações sociais, políticas e culturais (Pereira, 2004).

Neste sentido, a psicologia sócio-histórica compreende os sujeitos como constituídos historicamente, determinados pelas relações sócio-culturais e pelas relações que estabelecem em seu meio. Para esta corrente teórica, a juventude é entendida como uma construção social, constituída de significados culturais e características bio-fisiológicas, como "elementos para a conversão do social em individual e referências para a constituição da subjetividade do jovem e de seu mundo psíquico" (Stamato, 2008, p. 112).

A perspectiva sócio-histórica defende ainda o consenso de que não se pode falar em juventude, mas em juventudes, levando-se em conta as peculiaridades e a diversidade social em que tal categoria se 
expressa. Por isso, neste estudo fez-se o uso sociológico no plural para designar "juventudes", corroborando com Rezende (1989), para quem:

\begin{abstract}
Esta concepção alerta-nos sobre a existência, na realidade dos grupos sociais concretos, de uma pluralidade de juventudes: de cada recorte sociocultural - classe social, estrato, etnia, religião, mundo urbano ou rural, gênero e etc. - saltam subcategorias de indivíduos jovens, com características, símbolos, comportamentos, subculturas e sentimentos próprios. (Rezende, 1989, p: 4-5).
\end{abstract}

Seguindo esta mesma perspectiva, Groppo (2000, p.52) acrescenta que há múltiplas juventudes no chamado rural. Contudo, é fundamental compreender a juventude para além de uma fase de transformações fisiológicas, naturais e pré-definidas. Além disso, a participação dos jovens nos movimentos sociais rurais, entendida como um campo de possibilidades para a construção de projetos de vida fazem do tema "juventude rural" um território de buscas analíticas, para que se possa compreender o fenômeno de "ser jovem" no meio rural, em seus contextos de vida, tempo e espaço. Dessa forma, o que é ser jovem hoje é diferente do que era ser jovem há 20 anos atrás, pois suas representações e expectativas mudaram. Portanto, a juventude é uma categoria construída socialmente, ocasionando a sua mutabilidade espacial e temporalmente.

\title{
2.2 Projetos de vida
}

Segundo Velho (1994), o projeto de vida não é um fenômeno puramente interno, subjetivo. Ao contrário, é formulado dentro de um campo de possibilidades, que é dado com as alternativas construídas do processo sócio histórico que trabalha com a dimensão individual e coletiva e abarca não apenas o futuro, mas as dimensões do passado e do presente. Já que existe essa ligação das dimensões de tempo passadopresente - futuro, percebe-se que a maioria dos (as) jovens vincula seu projeto de vida ao movimento agroecológico pensando em "crescer" no movimento. Dessa forma, os projetos podem ser individuais ou coletivos; amplos ou restritos e com elaborações a curto ou médio prazo, de acordo com o campo de possibilidades. Logo, dependem dos contextos socioeconômico e cultural concretos em que cada jovem se encontra inserido, e que circunscrevem suas experiências.

Autores como Velho (1994) e Dayrell (2010) buscam articular o projeto de vida como elemento definidor da construção da identidade, a partir de uma perspectiva histórica e temporal. Estes autores enfatizam a necessidade de construir uma prática capaz de oportunizar o jovem a descobrir suas potencialidades e se perceber como agente de transformação da sociedade, pois "quanto mais o jovem se conhece, experimenta as suas potencialidades individuais, descobre o seu gosto, aquilo que sente prazer em fazer, maior será a sua capacidade de elaborar o seu projeto" (Dayrell, 2010, p.02). Compartilhando desta perspectiva, Troian (2014), destaca a heterogeneidade de percepções e a diversidade de projetos de vida construídos pelos jovens rurais e que nem sempre são desvinculados da sua permanência no rural. 
Se há por um lado a necessidade de considerar o campo de possibilidades, também é importante considerar as características individuais, os desejos, as aptidões. Por isso, não se pode utilizar a idéia de projeto de vida para nomear de forma fechada as manifestações dos jovens sobre suas perspectivas de futuro, mas para interpretar o modo como esses sujeitos se posicionam diante da necessidade de assumirem de forma autônoma a construção de seus projetos para o futuro. Trata-se de uma dinâmica que está intimamente ligada à construção da identidade que, segundo Dayrell (2010), é um processo de aprendizagem que implica no amadurecimento da capacidade de integrar o passado, o presente e o futuro, bem como as condições objetivas e subjetivas.

\section{METODO}

O presente estudo foi desenvolvido com os jovens rurais participantes do movimento agroecológico do município de Araponga, localizado na região da Zona da Mata Mineira. Esta pesquisa caracterizou-se por uma abordagem quali-quantitativa, utilizando metodologicamente de questionários, entrevistas e história de vida de jovens com idade entre 15 e 32 anos que participaram e atuaram no movimento agroecológico, nas comunidades de Salazar, São Joaquim e Praia Anta, do município de Araponga - MG.

A utilização da entrevista, orientada no sentido de buscar elementos da trajetória de vida dos jovens, potencializou as análises e perspectivas deste estudo. $O$ universo populacional constituiu-se de 125 jovens que participam dos movimentos sociais rurais no município. Para este estudo, a amostra foi composta de 45 jovens (26 rapazes e 19 moças), participantes do movimento agroecológico da região há no mínimo cinco anos, na faixa etária de 15 a 32 anos. 0 mapeamento dos (as) jovens do movimento agroecológico de Araponga se deu a partir do cadastro dos/das participantes no Sindicato dos Trabalhadores Rurais da cidade.

A técnica de coleta de dados consistiu na aplicação de questionários e entrevistas com os (as) jovens, procurando identificar características relevantes para o estudo, como a comunidade onde residem; idade; condição socioeconômica; acesso ao trabalho e estudo; a renda desses sujeitos; se eram casados e possuíam filhos. Além disso, os jovens entrevistados (as), responderam um roteiro com vinte perguntas, que versaram sobre as seguintes temáticas: inserção e vivência junto ao movimento agroecológico; questões de gênero; percepção da família sobre a participação dos jovens no movimento; motivações e expectativas dos jovens do movimento agroecológico, ou seja, de que forma os jovens do movimento elaboram seus projetos de vida.

Em todas as entrevistas, utilizou-se o gravador com a autorização do entrevistado, onde foi esclarecido sobre o objetivo da pesquisa por meio do Termo de Consentimento Livre e Esclarecido (TCLE), e principalmente, sobre o sigilo de seus nomes na mesma. O esforço empreendido ao longo desse estudo foi 
não só de observar, mas também de ouvir os jovens, por meio das técnicas de coleta de dados já explicitadas, no sentido de compreender, do seu ponto de vista, as questões que orientam esta investigação.

De posse das narrativas orais registradas com gravador de voz, estas foram posteriormente transcritas e submetidas à análise de conteúdo, conforme metodologia proposta por Bardin (2011). Para os dados quantitativos foram utilizadas análises estatísticas, basicamente, de natureza descritiva, em função do caráter diagnóstico da pesquisa.

\section{RESULTADOS E DISCUSSÃO}

\subsection{Trajetórias e Projetos de Vida do Jovem Agroecológico}

Para análise do universo dos jovens neste estudo, foi necessário entender a sua trajetória de vida e as mudanças que ocorreram em seu contexto social, que influenciaram diretamente na formulação de seus projetos de vida. A partir da amostra estudada, pôde-se detectar duas trajetórias sociais diferentes que se encontram no movimento agroecológico de Araponga -MG: a primeira será aqui denominada "jovem rural tradicional" e uma segunda denominada de "jovem rural migrante".

Pela designação utilizada, entende-se como "jovem agricultor tradicional" aquele jovem que percorreu toda a sua trajetória social no meio rural e tem como elemento constitutivo de sua identidade o pertencimento e enraizamento com o meio rural; e "jovem rural migrante" como aquele jovem que migrou para a cidade, teve um período de experiências urbanas e retornou posteriormente para a agricultura, como mostra o gráfico 01.

Gráfico 01: Trajetória Social do Jovem Rural, Araponga/MG, 2013.

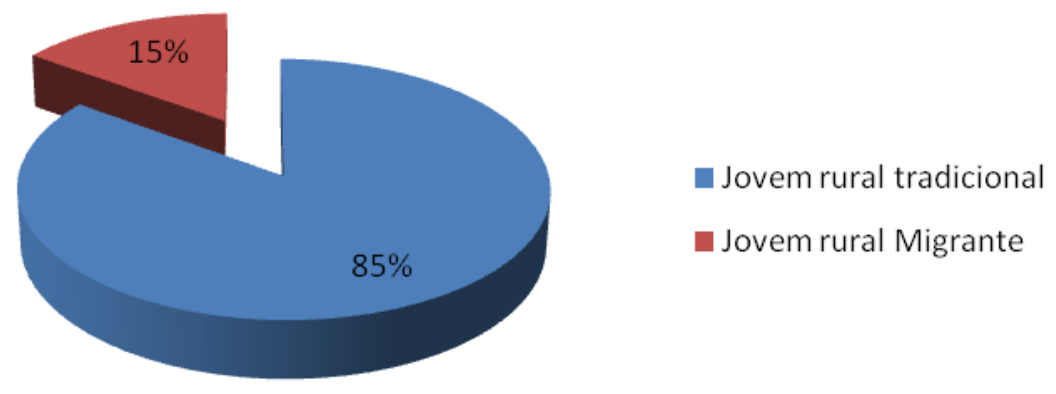

Fonte: Dados da Pesquisa, 2013.

No interior da categoria "jovem rural migrante" (15\%), composta pelos jovens que migraram para a cidade, tiveram experiências no meio urbano e em determinado momento optaram por retornar ao meio rural 
para trabalhar com agroecologia, foi identificada uma subcategoria, composta por $5 \%$ destes jovens em que, mesmo possuindo atividades urbanas, não houve um desligamento de suas raízes rurais, seja pelo vínculo e pertença com a terra de forma indireta, seja porque esta experiência ocorreu por um período curto de tempo, o que impossibilitou esta ruptura. Como neste último caso não ocorreu um rompimento com as raízes culturais do meio rural, parece mais adequado incluir estes jovens na categoria "jovem rural tradicional". Queiroz (1978) acrescenta que os costumes e hábitos não sofreriam um processo de transformação e sim de adaptação à nova realidade, ou seja, uma atualização da tradição.

Ao fazer a análise das trajetórias, presenciou-se a existência de grupos distintos de jovens. Um que se caracteriza pelo desejo de permanecer no meio rural, na comunidade onde reside e dá continuidade às atividades agroecológicas desenvolvidas pela família e outro grupo composto por jovens que desejam sair do meio rural em busca de emprego e melhores condições de vida para a família. A partir da existência destes dois grupos de jovens rurais, buscou-se examinar o discurso de cada grupo; ou seja, aqueles que desejam ficar e aqueles que desejam sair do meio rural.

Para os jovens que pretendem sair do meio rural, a insatisfação em viver nestas localidades e os principais fatores para sua saída são: a influência dos pais quanto à tomada de decisão na propriedade e na permanência em casa, a falta de renda própria, já que seu trabalho é visto como "ajuda", ausência de políticas públicas básicas, como lazer e a educação; além das limitadas condições estruturais (estradas, transporte) precárias. Também encontramos jovens que já passaram pela experiência de morar na cidade, mas acabaram voltando para suas comunidades de origem, alegando que na cidade a vida é difícil, pois 0 trabalho não compensava ficar longe da família. Mesmo quando questionados quanto ao futuro, sem muita reflexão responderam que pretendem sair do meio rural.

Para o grupo de jovens que pretende ficar no meio rural, fica evidente 0 apoio e 0 incentivo dos pais, como também do próprio movimento agroecológico para que ele continue na agroecologia e para que 0 "trabalho" da família não se perca. Percebe-se, que há diálogo entre o jovem e a família e que todos participam da tomada de decisão sobre o que produzir como comercializar a produção e gerar renda para a família. Como projeto de vida este jovem pretende ampliar sua produção agroecológica e desenvolver 0 turismo rural dentro da propriedade, com o objetivo de agregar valor aos produtos e gerar renda para toda a família. A partir das análises dos dois discursos, pode-se verificar que, enquanto os jovens que querem ir embora "ajuda" a família, os jovens que querem ficar "trabalha".

Nota-se, que estas são diferenças qualitativas importantes neste contexto, pois "ajudar" não dá satisfação, reconhecimento e nem renda para o jovem, ao passo que "trabalhar" permite ao jovem ter um reconhecimento, uma importância maior na família e uma renda própria. Quando perguntados sobre os fatores que influenciaram os jovens e seus familiares a optarem pela produção agroecológica, os jovens 
apontaram os fatores econômicos, os ligados à saúde da família e do consumidor e fatores relacionados com a proteção da natureza, como na tabela a seguir:

Tabela 1 - Fatores determinantes da opção pela produção agroecológica, Araponga/MG, 2013.

\begin{tabular}{ccc}
\hline Fatores & Valores & Porcentagem \\
\hline Econômicos & 11 & $24.4 \%$ \\
$\begin{array}{c}\text { Saúde da família e do } \\
\text { consumidor }\end{array}$ & 2 & $44.5 \%$ \\
Proteção da natureza & 14 & $31.1 \%$ \\
\hline Total & 45 & 100 \\
\hline
\end{tabular}

Fonte: Dados da Pesquisa, 2013.

Conforme a Tabela 1, predominou a preocupação com a saúde (44,5\%). Assim, a decisão de produzir sob a ótica da agroecologia se deve preferencialmente a fatores relacionados à saúde da família e do próprio consumidor de seus produtos, que passam a adquirir hortaliças, legumes e frutas isentas de agrotóxico ou adubação química. $\mathrm{O}$ consumo destes alimentos ultrapassa a preocupação com uma alimentação saudável e com a segurança alimentar, mas também enfoca a preservação do meio ambiente, em detrimento ao modelo monocultor do agronegócio. Iniciativas "agroecológicas", como o resgate e a manutenção de sementes pelas famílias agricultoras, a conservação de recursos naturais, a produção de alimentos limpos e a articulação de novas redes de distribuição e consumo de alimentos são condições sine qua non para garantir o acesso de alimentos de qualidade a todos, garantindo a segurança alimentar.

Já para $24,4 \%$ destes jovens, o fator econômico foi relevante nesta tomada de decisão, pois com a produção agroecológica houve um aumento da renda de suas famílias, que conseguiram agregar valor aos produtos comercializados nas feiras e comércios da cidade. Para os $31,1 \%$ restantes, o fator ambiental foi 0 que mais peso teve na sua decisão, pela relação que a produção agroecológica estabelece com a natureza, preservando os recursos naturais locais e assegurando a manutenção da diversidade biológica, da qualidade do ar, da água e do solo e, consequentemente, a saúde e qualidade de vida das famílias rurais.

Acredita-se que, o movimento agroecológico trouxe uma repercussão positiva na vida dos jovens, de suas famílias e da comunidade de forma geral, pois, na medida em que passaram a incorporar e legitimar os saberes e práticas agroecológicas em seu cotidiano foram, também, despertados para as potencialidades presentes no local, isto é, o potencial endógeno da região e ponto de partida para iniciativas e ações voltadas para o desenvolvimento rural do município. 
Deste modo, as ações desenvolvidas pelos jovens no movimento agroecológico vão desde o trabalho de agregar valor à produção, recuperar solos degradados através da redução de agrotóxicos e implantação dos sistemas agroflorestais (SAFs) ${ }^{4}$, distribuir e comercializar produtos agroecológicos nas feiras até a proposição de políticas públicas que estimulem a tomada de decisão sobre o que produzir, como comercializar e obter melhorias em sua propriedade. $O$ trabalho do jovem passa a ter também uma dimensão educativa, conquistando seu espaço e autonomia em relação à unidade familiar, envolvendo a participação de todos os membros nos processos de planejamento, administração dos recursos e difusão do saber agroecológico.

Leff (2002, p.37), também aponta que "estes saberes e estas práticas não se unificam em torno de uma ciência: as condições históricas de sua produção estão articuladas em diferentes níveis de produção teórica e ação política". Logo, o saber do jovem agroecológico está circunscrito em um saber camponês, que, segundo Velho (1999), está impregnado de valores que não apenas estabelecem princípios e técnicas de trabalho, mas que estão na base de toda a cultura camponesa, definida por um modo de vida especifico baseado nas relações do homem com a terra e dos homens entre si. Assim, o rompimento desse saber eliminaria não só um know-how agrícola, tornando-o inútil, mas toda uma visão de mundo e os projetos de almejados pelos jovens.

Para Velho (1994), a categoria projeto de vida caracteriza-se como uma metamorfose em um processo temporal a partir da memória do ator e dos meios para alcançar o projeto, não se limitando apenas as aspirações. De acordo com as considerações de D'Angelo (1994), o projeto de vida pode ser definido a partir da perspectiva multidimensional, integrando as dimensões psicológica e social, como também a maneira de agir do sujeito em seu contexto relacional com a sociedade. Desta forma, o projeto de vida pode ser comparado a uma folha em branco que vai sendo preenchida de acordo com as experiências do ser humano ao longo da vida. Assim, os projetos nascem e ganham consistência em relação às situações passadas e presentes, com vistas às futuras condições.

Ao serem perguntados sobre seus planos para o futuro, ou seja, quais são seus projetos de vida, os jovens mostraram que, em grande parte, pretendem dar continuidade aos seus estudos, buscando maior profissionalização, tanto para retornar à propriedade agrícola e desenvolver uma ação mais qualificada (53\%), quanto para empreender um negócio na área urbana (20\%), como se pode observar na Tabela 2 :

\footnotetext{
${ }^{4}$ Sistema de manejo sustentado da terra que aumenta o seu rendimento, combinando a produção de plantas florestais com cultivos agrícolas e/ou animais, simultânea ou consecutivamente, de forma deliberada, na mesma unidade de terreno, envolvendo práticas de manejo em consonância com a população local (MEDRADO, 2000).
} 
Tabela 2 - Relação dos Projetos de Vida dos jovens do Movimento Agroecológico, Araponga/MG, 2013.

\begin{tabular}{lccc}
\hline \multicolumn{1}{c}{ Projetos } & Valores & Porcentagem \\
\hline Pretende estudar mais e montar um negócio próprio na cidade & 9 & $20 \%$ \\
Pretende estudar e voltar à propriedade & 24 & $53 \%$ \\
Pretende continuar o trabalho no campo, na propriedade de seus familiares. & 7 & $16 \%$ \\
Pretende abandonar o trabalho no campo e ter um trabalho assalariado na cidade & 5 & $11 \%$ \\
\hline Total & 45 & 100 \\
\hline
\end{tabular}

Fonte: Dados da Pesquisa, 2013.

Em termos de projetos de vida também não se descartou, por um lado, o abandono da vida no campo pelos jovens rurais para ter uma atividade assalariada na cidade, o que vai ao encontro dos resultados encontrados por Ramos et al (2018), ao apontar que no contexto econômico da atividade fumageira observou-se uma descrença por parte dos jovens de que agricultura de pequena escala tenha capacidade financeira de prover seu sustento no futuro. Por outro lado, para aqueles jovens que desejam permanecer no campo, como agricultores familiares, apesar de reconhecerem as dificuldades que irão enfrentar, pretendem adotar práticas diferentes dos seus pais, como a adoção de atividades pluriativas que ampliem as suas possibilidades de escolha para a sua permanência no meio rural.

Ao analisar os projetos de vida dos jovens de São Joaquim, Salazar e Praia d'Anta que atuam no movimento agroecológico, nota-se que seus projetos de vida falam da permanência no campo, pois estão direta ou indiretamente relacionados ao mundo rural agrícola, não apenas como um destino, mas também como uma escolha. No entanto, nem todo jovem do movimento quer ser agricultor como seus pais, como expressa um dos jovens entrevistados.

Além disso, o município de Araponga - MG é uma região que se caracteriza pela agricultura familiar e pelos princípios da agroecologia, o que acaba direcionando os projetos de vida dos jovens para permanecerem no campo, sendo incentivados por uma educação do campo voltada para o mundo rural. Esses projetos representam uma mudança de comportamento em relação às formas tradicionais de produção, já que muitos destes jovens mostraram o interesse de permanecer no campo, como agricultor ou administrador familiar.

Vários estudos têm mostrado que, o movimento migratório dos jovens rurais para cidade não resolve o "problema" de nenhum dos lados: na cidade aumentam-se os índices de violência, miséria e desemprego; na área rural o decréscimo da produção agrícola, diminuição da população e mão de obra rural e aumento do custo de vida. Em decorrência disso, Santori (2008), ressalta a importância de os jovens tornarem-se 
protagonistas capazes de promover discussões nas suas comunidades, problematizando suas localidades para a melhoria da qualidade de vida do meio rural.

Acrescenta-se ainda que, entre os jovens entrevistados, há uma diversidade de projetos, estes consideram tanto a dimensão individual quanto a coletiva. Vale ressaltar, que os projetos individuais que visam crescer no movimento como protagonistas de ações em prol da comunidade não anulam projetos mais individuais, como casar e ter filhos; porém, para a maioria das jovens, o casamento e a maternidade não ocupam mais lugar central em seus projetos de vida.

As jovens entrevistadas ressaltam a importância de estudar, de concentrar sua dedicação e seu esforço na busca pela realização de seus anseios futuros sejam profissionais ou de inserção no mercado de trabalho:

Eu quero terminar meus estudos aqui na Escola Família Agrícola (EFA), formar e montar um negócio para mim e minha família. Construir uma casa e ter o meu próprio canto. Ser independente! Entendeu? (Respondente 01, rapaz, 19 anos).

Nessa fala, fica evidente o caráter educativo do movimento, tratado a partir das seguintes dimensões, sugeridas por Almeida (2009): construção da cidadania, da cultura política, da configuração do cenário sociopolítico e econômico, da subjetividade e da organização política. Desta forma, as ações desenvolvidas no movimento acionam processos de conscientização para o agir coletivo, de (re) construção de concepções sobre o mundo e de investimento na formação do ser humano, preparando-o para o enfrentamento político das adversidades da vida.

Conforme Redin (2012), o trabalho desenvolvido pelas associações e movimentos sociais conduz os jovens a manterem vínculos com o rural, bem como busca enfatizar a necessidade de políticas públicas voltadas não somente para o espaço da produção e do trabalho, mas também para o fortalecimento dos espaços de sociabilidade no desenvolvimento do protagonismo juvenil. Loreto et al (2018), complementa que, por meio das atividades vivenciadas junto aos movimentos sociais, a juventude pode conseguir ampliar seus conhecimentos, principalmente sobre políticas públicas, permitindo acessá-las.

Castro e Correa (2005) destacam que falar do futuro, sobre planos e expectativas de vida dos jovens para o porvir é um modo de apreender o que estes trazem como valores e perspectivas para sua vida e a partir desta orientação ouvir o que eles/elas pensam e o que sonham para o futuro, em meio a tantas dificuldades vivenciadas no presente. De acordo com as transformações vivenciadas pelos jovens ao longo desse processo, seus projetos podem mudar isso porque são essencialmente dinâmicos, como destaca Velho (1994), ao afirmar que o projeto é permanentemente reelaborado por meio de novos sentidos e significados, com repercussões na identidade.

Em relação aos seus projetos de vida, os (as) entrevistados (as) fazem referência ao movimento agroecológico, ou seja, ressaltam a importância do movimento agroecológico em canalizar o potencial criador 
dos jovens para as atividades em prol da comunidade em que vivem, contribuindo para a sua permanência e a reprodução social da agricultura familiar no município, além de destacarem a vontade de crescer e serem reconhecidos (as) dentro e fora do movimento.

A maioria dos jovens ressaltou que, a sua inserção no movimento agroecológico trouxe transformações positivas tanto em seus projetos de vida, quanto em suas trajetórias e redes de relações sociais. Uma das jovens afirma que a entrada no movimento possibilitou mudanças positivas em seu contexto de vida, ressaltando a importância do movimento em sua trajetória:

"[...] Antigamente eu não acreditava que pudesse ficar aqui na roça, trabalhar com minha família e ser feliz, mas aí depois que eu conheci o movimento eu mudei bastante o jeito de entender as coisas, se valorizar, se respeitar e viver em comunidade. Tomei gosto pela produção agroecológica, e hoje trabalho em uma horta comunitária que vende o que produz para as escolas daqui da região. Aí mudei totalmente minha cabeça, ainda bem. [Risos]" (Respondente 06, moça, 21 anos).

Estes resultados vêm de encontro com as idéias de Manhani (2000), ao afirmar que, após participarem dos movimentos sociais rurais, os jovens demonstram mais disposição em permanecer nas atividades agrícolas e agroindustriais, incorporando conhecimentos que eram aplicados em suas unidades produtivas, geralmente com a introdução de novas técnicas, que resultaram em mudanças nas condições materiais das famílias e na redução da tendência de migração.

Sendo assim, o movimento agroecológico despertou na maioria dos jovens mudanças subjetivas em termos de estima social (empoderamento), prática da reflexão ou no estado de ânimo e autoconfiança, além de mudanças objetivas como: dominar os ensinamentos da agroecologia, se formar, casar, ter filhos e ser independente, proporcionadas pelas ações e práticas do movimento em suas trajetórias de vida.

Já os planos "no interior do movimento" estão diretamente relacionados à capacidade dos (as) jovens de se fortalecerem enquanto coletivo organizado, através da criação de uma rede de apoio, principalmente familiares, a escola e os amigos. Considerando a complexidade da agricultura contemporânea, os movimentos sociais rurais se apresentam como agentes centrais da renovação social. Nesse contexto, os jovens rurais adquirem relevância estratégica, pois suas ações contribuem na reflexão sobre a realidade concreta, seja por apontarem problemas vivenciados, seja por produzirem novas agendas com respeito a Estado e à sociedade civil e por apontarem a necessidade da sustentabilidade das propostas de futuro.

Constatou-se, neste estudo, que a maioria dos jovens entrevistados possui um projeto agroecológico de vida, o que Ihes permite mesclar a racionalidade econômica com a racionalidade sócio ambiental, encontrando na agricultura familiar um campo fértil para o exercício dos princípios da agroecologia, o que cria as condições necessárias para que a unidade de produção passe a ser entendida em primeiro lugar como uma unidade de vida digna. Neste âmbito, tomando como base a realidade do movimento agroecológico de Araponga-MG, esses jovens procuram construir sua forma de ver e viver o mundo a partir de suas 
experiências circunscritas em um processo contínuo de transformações pessoais, que somadas a sua trajetória de vida, direcionam suas escolhas.

Observou-se também que há uma hibridez entre o uso das oportunidades do espaço rural e o urbano, ou seja, as fronteiras rurais e urbanas estão constantemente diluídas nos projetos de vida dos jovens que participam do movimento agroecológico, já que inserção destes nos movimentos sociais rurais abre um campo de possibilidades para atuarem politicamente em sua comunidade e na sede urbana do município. No processo de formação e de partilha de experiências entre os jovens rurais e urbanos, o movimento possibilita que muitos deles se esclareçam e conquistem condições para a melhoria da qualidade de vida de sua família através do estímulo ao desenvolvimento do protagonismo e autonomia na tomada de decisão.

\subsection{O Jovem Rural no Movimento Agroecológico: Limites e possibilidades}

Ao serem perguntados sobre os motivos que os levaram ao participar do movimento, quase $80 \%$ dos jovens entrevistados afirmaram o fato de ser algo "novo" diferente da agricultura convencional e também por incentivo da família; 20\% relataram ser por influência da Escola Família Agrícola (EFA) e do Sindicato dos Trabalhadores rurais, como mostra os depoimentos abaixo:

"Gosto de conhecer coisas novas e aprender mais! Aqui no movimento, eu e meus amigos temos esta oportunidade! Enfatiza! (Respondente 12, moça, 18 anos).

Esse "novo" para estes jovens também está relacionado no sentido de sair da rotina, fazer outras atividades que não estejam ligadas ao âmbito familiar, como atividades recreativas e de lazer. Além disso, ao inserir no movimento, o jovem encontra outros jovens, o que permite a possibilidade de relacionamentos futuros. A maioria dos jovens trabalham juntamente com seus familiares as práticas agroecológicas em suas propriedades. Essas propriedades têm em média 12 hectares e constituem a base para a sobrevivência de muitas famílias que se dedicam à produção de café, culturas de milho, feijão e a criação de gado.

Portanto, 0 fato dos agricultores serem legitimados proprietários, reflete os avanços na democratização do acesso à terra pelos movimentos sociais da região. Neste sentido, a terra é elemento fundamental para a definição das trajetórias de vida e estratégias de sobrevivência dos jovens rurais que participam do movimento agroecológico, pois constitui também um elemento definidor nas relações com os agricultores, com a família e também com outros movimentos sociais.

Vale ressaltar que todos esses (as) jovens nasceram em famílias que participaram da luta pela terra desde a formação dos movimentos sociais rurais na Zona da Mata de Mineira a partir da década de 1980, intensificada por diversas experiências que vão desde a conscientização de seus direitos até a construção da Escola Família Agrícola em 2008, na comunidade de São Joaquim, Araponga, MG. Logo, a participação e o 
envolvimento das famílias são uma marca do movimento desde sua gênese, seja na partilha do conhecimento agroecológico, seja no fortalecimento da agricultura familiar na região.

Nas comunidades de São Joaquim, Praia d'Anta e Salazar, a família se constitui como um espaço de vida, trabalho, socialização e também de conflito quanto à administração e gestão da propriedade. Logo, o jovem que não consegue o apoio da família em casa, possivelmente não irá conseguir desenvolver suas potencialidades e experiências que vão além das ações coletivas do movimento.

Minha família é tudo para mim, porque é com eles que resolvo meus problemas e posso confiar inteiramente "né"? (Respondente 03, moça, 18 anos).

A partir da análise dos dados levantados, foi possível constatar a importância da família e do movimento agroecológico como uma rede de apoio dos (as) jovens entrevistados (as). As famílias dos jovens exercem um papel fundamental na escolha dos jovens de ficar ou sair da terra, na forma como se dedica ao trabalho e nos seus projetos futuros.

Segundo Schneider (2003), é no âmbito familiar que se discute e se organiza a inserção produtiva, laboral, social e moral de seus membros, sendo também, em função desse referencial que são estabelecidas as estratégias individuais e coletivas que visam garantir a reprodução social do grupo familiar e a vida em comunidade, ou seja, o sentimento de pertencimento a comunidade se configura como um espaço formativo da identidade juvenil, na medida em que permite ao jovem estabelecer contatos com outras formas organizativas, como ressalta uma das lideranças do movimento:

Os jovens são importantes na nossa comunidade e principalmente no movimento, pois renovam as ações e possibilita a contribuição coletiva (Respondente 05, homem, 44 anos).

A partir dos depoimentos dos jovens, houve um maior interesse pelo estudo em áreas relacionadas ao meio rural (técnico em meio ambiente, técnico em agropecuária, engenharia florestal, agronomia e agroecologia), pela produção de sementes agroecológicas e organização de feiras livres, o que tornou possível comercializar a produção diretamente aos consumidores, garantindo a melhoria da qualidade de vida de suas famílias, e em contrapartida das famílias que consomem os seus produtos. Estas e outras práticas foram se constituindo enquanto elementos chaves na organização social e no resgate e valorização da identidade dos jovens rurais envolvidos no movimento agroecológico.

Com base nestas observações, pode-se inferir que o movimento social rural, assim como 0 movimento agroecológico, tornou-se um espaço de formação educativa e reflexiva da realidade em que vivem. Neste aspecto, Silva (1998, p.106), esclarece que a principal contribuição do movimento agroecológico não está na criação de novas tecnologias ditas alternativas ou sustentáveis, mas na criação de uma nova consciência social a respeito das relações das pessoas com a natureza.

Segundo Wanderley (2000, p.02), é na "apreensão da diversidade e da complexidade do rural, como um espaço próprio gestor de um modo de vida diferenciado daquele produzido no espaço urbano, que será 
viável a noção de cidadania, sendo compartilhada legitimamente pelo rural". Para a autora, o estudo dessa nova ruralidade supõe a compreensão dos contornos, das especificidades e das representações deste espaço rural, entendido, ao mesmo tempo, como espaço físico (referência à ocupação do território e aos seus símbolos), lugar onde se vive (particularidades do modo de vida e referência identitária) e lugar de onde se vê e se vive o mundo (a cidadania do homem rural e sua inserção nas esferas mais amplas da sociedade).

$\mathrm{Na}$ intenção de levantar algumas indagações sobre o cotidiano dos jovens do movimento agroecológico do município, foi solicitado que eles falassem sobre a sua atuação e as atividades que exercem no interior do movimento social. Dentre as respostas dadas, o destaque ficou para as atividades de cunho coletivo e social, como as práticas e manejo agroecológico nas propriedades, a elaboração e promoção de dias de campo no município e a participação em eventos relacionados aos movimentos sociais, como a troca de saberes ${ }^{5}$, realizada anualmente, durante a Semana do Fazendeiro na Universidade Federal de Viçosa.

De acordo com Castro (2005, p.375), é nessas situações coletivas em que os jovens brincam, trabalham, participam de reuniões e encontros, percebem que "a categoria jovem aparece como uma identificação coletiva que unifica a ação, podendo ser lida, nesse contexto, como 'categoria social em construção', ainda que não tenha se materializado em um grupo formal". Portanto, para a mesma autora, esses espaços contribuem para a "descoberta de um mundo rural prazeroso".

Ao serem questionados sobre o futuro do movimento agroecológico e da própria agricultura familiar no município, moças e rapazes afirmaram que o futuro da agricultura na região depende da forma como os jovens a vêem hoje, já que os saberes e troca de experiências proporcionadas pelo EFA e pelo próprio movimento agroecológico, ajudam a construir uma visão mais otimista quanto às incertezas do futuro e se sentem mais seguros quanto a sua permanência no campo.

Mesmo sabendo que estes jovens são fortemente influenciados pela cultura de massa, que busca incentivar um padrão de vida que afasta os jovens rurais de sua realidade, os espaços de discussão do movimento agroecológico têm buscado proporcionar aos jovens um espaço agradável e de interação com o grupo. Com respeito à participação social e política dos jovens no interior do movimento agroecológico, todos os jovens entrevistados declararam possuir alguma participação social no movimento, a partir de sua representação e de seu poder decisório, seja como integrante ou liderança do movimento. Através da participação, os jovens constroem uma identificação como atores sociais e passam a representar os interesses e demandas do movimento nos conselhos municipais, instituições de crédito e debates políticos.

\footnotetext{
${ }^{5}$ A Troca de Saberes é uma estratégia pedagógica de extensão universitária que tem como objetivo a socialização das pesquisas produzidas na universidade com agricultores da região e outros sujeitos envolvidos; a ampliação da concepção de interdisciplinaridade junto aos pesquisadores, grupos de agroecologia e em geral da comunidade acadêmica.
} 
Além disso, através da sua atuação e participação, os jovens passam a ser reconhecidos como responsáveis, superando o preconceito em relação ao jovem como "sinônimo de problema" e de "rebeldia sem causa".

De acordo com Castro e Abramoway (2009, p. 31), há duas situações de participação da juventude, interpretadas como formas de aprendizado do protagonismo juvenil: "uma primeira, de caráter individual, quando o jovem participa falando, escrevendo, discutindo, denunciando, cobrando responsabilidades, encorajando os tímidos e indecisos e uma segunda de caráter coletivo, gerada por meio de grupos com objetivos definidos e disposição para trabalharem no âmbito social".

Partindo dessas análises, a participação dos jovens no desenvolvimento das ações no movimento agroecológico é também um processo de aprendizagem, pois estes jovens agricultores são capazes de refletir organizadamente sobre seus problemas concretos e, embasados em seus saberes e conhecimentos, desenvolvem soluções, que exigem uma ampla organização social e política, de forma que o capital cultural possa se converter em capital social (Bourdieu, 1983).

No entanto, estes jovens enfrentam alguns problemas em relação ao desenvolvimento do trabalho e das práticas agroecológicas em suas propriedades. As limitações apontadas foram: a dificuldade financeira para o cultivo de suas lavouras, a ausência de políticas públicas para o jovem do campo, a instabilidade no preço dos produtos agroecológicos e a sazonalidade e baixa produção em períodos de seca, o que dificulta a garantia e continuidade da oferta dos produtos nos mercados e feiras.

Com relação à principal ocupação exercida pelos jovens agroecológicos, pode-se destacar que a maioria dos jovens estuda e trabalha nas propriedades agrícolas da família $(57,8 \%)$, como mostra as respostas sintetizadas na tabela 3 .

Tabela 3 - Principal atividade dos jovens do Movimento Agroecológico, Araponga/MG, 2013.

\begin{tabular}{ccccc}
\hline Principal atividade dos jovens & $\begin{array}{c}\text { Número de } \\
\text { jovens }\end{array}$ & Moças & Rapazes & Porcentagem \\
\hline $\begin{array}{c}\text { Estuda e trabalha com remuneração nas atividades de produção } \\
\text { agroecológica dentro da propriedade }\end{array}$ & 26 & 10 & 16 & $57.8 \%$ \\
Estuda e ajuda nas tarefas domésticas & 11 & 9 & 2 & $24.4 \%$ \\
Só estuda & 8 & 5 & 3 & $17.8 \%$ \\
\hline Total & 45 & & & 100 \\
\hline
\end{tabular}

Fonte: Dados da Pesquisa, 2013. 
Os resultados também mostraram que os jovens possuem atividades ocupacionais diretamente ligadas ao trabalho no meio rural e recebem alguma remuneração em troca. Também foi significativo 0 número de jovens que indicaram estudar e ajudar nas tarefas domésticas (24.4\%) e somente estudar $(17.8 \%)$.

O fato das moças "ajudarem" nas atividades domésticas e os rapazes "trabalharem" nas atividades produtivas, como mostra a Tabela 3, revela uma diferenciação valorativa do trabalho, o que acaba refletindo também uma diferença de gênero. Mesmo que, a unidade familiar se organize através do trabalho conjunto dos seus membros, as mulheres exercem um papel fundamental nas atividades que realizam, seja no espaço doméstico, produtivo e reprodutivo. No entanto, essas atividades são caracterizadas como uma obrigação natural ou até mesmo como "ajuda". Tal situação acaba por reforçar a divisão sexual do trabalho e a invisibilidade da mulher no espaço rural.

Durante a realização da pesquisa com os (as) jovens agroecológicos das comunidades estudadas pôde-se verificar a tendência da divisão sexual do trabalho nas atividades desenvolvidas pelos (as) jovens no movimento. As jovens mulheres cuidam do trabalho doméstico e também ajudam no trabalho produtivo da roça, enquanto os homens cuidam apenas do trabalho da roça. Ainda assim, as jovens do movimento agroecológico estão conseguindo avançar na participação da produção e comercialização dos produtos, buscando diversificar o cultivo, através da recuperação de espécies de hortaliças e outras culturas extintas na região.

Observou-se que, nas propriedades que trabalham apenas com a agricultura agroecológica, as mulheres participam desde o manejo com o solo até a comercialização dos produtos agroecológicos, ou seja, participam de todo o processo, ao contrário de quando trabalhavam com agricultura convencional. Essa constatação desconstrói a imagem da mulher enquanto vítima, demonstrando importantes avanços construídos na busca da promoção de igualdade entre homens e mulheres no meio rural. Apesar da desigualdade verificada no estudo em relação à remuneração e a realização das atividades domésticas, evidenciou-se uma tendência ao equilíbrio nas relações de gênero e de poder em relação à participação das jovens na cadeia produtiva agroecológica.

Conforme menciona Boni (2006), as famílias residentes nas propriedades rurais apresentam uma clara divisão do trabalho, uma vez que, o trabalho que antes era feito nas lavouras, passa a ser realizado próximo da casa, permitindo compatibilizar melhor esta atividade com os afazeres domésticos e demais responsabilidades tidas como femininas. A proximidade entre esses trabalhos, o "produtivo" e o "reprodutivo", acaba por confundi-los, fazendo com que as tarefas ligadas ao artesanato, o cuidado com a horta e a preparação de alimentos para a venda nas feiras, sejam consideradas quase como uma extensão do doméstico. Torna-se importante incorporar nesta análise a perspectiva de gênero, pois permite problematizar 
as diferenças construídas socialmente entre homens e mulheres, que muitas vezes são ditas como naturalizadas (Brumer \& Paulilo, 2004).

Vários estudos têm mostrado que as relações de trabalho são reforçadas pelo modo de produção capitalista e acentuam cada vez mais as relações de gênero. As formas de representação das diferenças entre homens e mulheres são, portanto, socialmente produzidas e podem ser mudadas porque são construídas e reconstruídas nas práticas sociais. Souza-Lobo (1991) debruça-se sobre a análise dos movimentos sociais articulada à categoria gênero, por considerá-los espaços importantes que rompem, ao nível das relações de produção, com o caráter estereotipado de que os homens são os únicos sujeitos políticos ativos que reivindicam direitos trabalhistas essenciais. Em tais espaços, pode-se perceber que as relações de gênero são também relações de poder, ao estabelecerem diferenças, assimetrias e hierarquias perante os sexos.

As questões relacionadas à produção (que compreende os processos do capital e do trabalho na constituição da mercadoria) seriam preocupações masculinas, já aquelas relacionadas à reprodução (pensada enquanto reprodução da vida e da força de trabalho do trabalhador enquanto tal) estariam diretamente vinculadas às mulheres. Contudo, tem ganhado força a separação entre produção-reprodução, com a imbricação entre práticas produtivas e reprodutivas, e que, por isso, o formato e a dinâmica dos movimentos sociais estão relacionados com as experiências cotidianas dos sujeitos, pois "as práticas masculinas ou femininas moldam e são moldadas de acordo com as formas dos movimentos, que vai aos poucos perdendo a figura masculina e o imaginário social vai absorvendo também a imagem das mulheres enquanto sujeitos reivindicativos, engajadas em lutas por melhorias nas condições de trabalho" (Souza-Lobo, 1991, p. 179).

A partir dessa análise, pode-se dizer que a gestão da unidade produtiva, tradicionalmente concebida como um papel masculino passa a ser reclamada como exercício da democracia, principalmente pelas mulheres, sobre as quais pesam discriminações de gênero. Se para os jovens, de forma geral, o trabalho carrega significados, como necessidade, autoestima e independência, a condição de "ajudantes" na qual os jovens e as jovens rurais são submetidos perante seus pais, tende a reforçar uma tendência, cada vez mais presente no meio rural, de envelhecimento e masculinização, considerando-se que são as jovens mulheres as mais afetadas nesse processo de exclusão, fazendo que vislumbrem um futuro mais promissor na cidade (Boni, 2006). 


\section{CONCLUSÕES}

De forma geral, pode-se concluir que movimento agroecológico de Araponga-MG possui uma significativa influência na configuração dos projetos de vida dos jovens rurais, que, em sua grande maioria, organiza e alinha seus projetos de vida orientados pela possibilidade de aplicação dos princípios agroecológicos em suas vidas. Para a maioria dos jovens, essa influência se dá no desejo de permanecerem no meio rural e terem seu negócio próprio. Além disso, o movimento agroecológico faz parte dos projetos de vida dos (as) jovens, nas perspectivas individuais ou coletiva. Diretamente, o movimento influi na capacidade dos jovens em se fortalecer enquanto um coletivo diferenciado. Ao viabilizar maior densidade relacional, representada principalmente pela rede familiar e comunitária (vizinhos e amigos), o movimento abre novas possibilidades e perspectivas de vida.

Entretanto, dependendo dos contextos vividos e dos significados atribuídos à vida no meio rural, das condições concretas de reprodução social da família, do relacionamento intra e extrafamiliar, os projetos de vida dos (as) jovens estão orientados para a saída ou permanência no campo. Ao adotar as práticas orientadas pelos princípios da agroecologia e quando as condições da família assim permitem, seus projetos de vida não são orientados exclusivamente por uma racionalidade econômica, mas reconstroem relações que reforçam as raízes numa condição de vida familiar pautada pelas relações de trabalho, de reciprocidade e pela tradição 6 que perpassa gerações.

A preservação e permanência da tradição se dão pelos rituais que, reinventados, reformulados e reincorporados, são entendidos como mecanismos da memória coletiva de um determinado grupo. Embora sejam múltiplos os modos de ser jovem neste contexto, esta pesquisa apontou que os jovens participantes do movimento agroecológico manifestaram uma forte preocupação com o futuro e ressaltaram que 0 trabalho, lazer, profissão, renda e autonomia são valores importantes a serem considerados nos projetos de vida, configurando uma visão ampla dos jovens sobre o tema.

A participação e as ações protagonizadas por estes jovens no movimento agroecológico em Araponga têm colaborado para o maior engajamento dos participantes e a criação de novos espaços para 0 debate acerca das Políticas Públicas para a Juventude Rural, abrindo um campo de possibilidades para os (as) jovens atuarem politicamente em sua comunidade. Portanto, muitos jovens, antes com mínimas perspectivas de fixação no campo, conseguiram superar as dificuldades e conquistaram condições para a melhoria da qualidade de vida de suas famílias através do estímulo ao desenvolvimento do protagonismo e autonomia na tomada de decisão.

\footnotetext{
6 O conceito de tradição, fundamentado em Beck et al (1997, p. 80), significa uma orientação para o passado, de tal forma que o passado tem uma pesada influência para o presente".
} 


\section{REFERÊNCIAS}

Abramo, H. \& Branco, P. (2005). Retratos da Juventude Brasileira: análise de uma pesquisa nacional. São Paulo: Perseu Abramo.

Abramovay, M. (2002). Juventude, violência e vulnerabilidade social na América Latina: desafios para políticas públicas. Brasília: UNESCO, BID.

Almeida, D. M. (2009). Entre ações coletivas e subjetividade: o caráter educativo dos movimentos sociais. ECCOS Revista Científica, 11(1), 141-156.

Balsadi, O.V. (2001). Mudanças no meio rural e desafios para o desenvolvimento sustentável. São Paulo em Perspectiva, 15 (1), 155-165.

Bardin, L. (2011). Análise de conteúdo. SP: Edições 70.

Beck, U.; Giddens, A. \& Lash, S. (2012). Modernidade reflexiva: política, tradição e estética na ordem social moderna. São Paulo: Unesp.

Boni, V. (2006). "Agroindústrias Familiares: uma perspectiva de gênero". In: $30^{\circ}$ Encontro Anual da ANPOCS (140-152), Caxambu.

Bourdieu, P. (1983). Questões da Sociologia. Rio de Janeiro: Editora Marco Zero Limitada.

Brumer, A.; Paulilo, M.I. (2004). As agricultoras do Sul do Brasil. In: Revista de Estudos Feministas, 7(12), 171 -174 .

Carneiro, M.J. (1998). Ruralidade: novas identidades em construção. Estudos Sociedade e Agricultura, 11 (2) ,53-75.

Carneiro, M.J. (1999) "O ideal Rurbano: campo e cidade no imaginário de jovens rurais". In: Silva, Francisco C.; Santos, Raimundo; Costa, Flávio de C. (org). Mundo Rural e Política: ensaios interdisciplinares. Rio de Janeiro.

Carneiro, M.J. (2005). Juventude rural: projetos e valores. In: ABRAMO, H.; BRANCO, P. P. M. (Org.). Retratos da juventude brasileira: análises de uma pesquisa nacional. São Paulo: Fundação Perseu Abramo.

Castro, E.G. (2005). Entre Ficar e Sair: uma etnografia da construção social da categoria jovem rural. Tese (Doutorado em Programa de Pós-Graduação em Antropologia Social). Rio de Janeiro: PPGAS/MN/UFRJ.

Castro, E.G. (2009). Juventude Rural no Brasil: processos de exclusão e a construção de um ator político. Revista Latinoamericana de Ciencias Sociales, Niñez y Juventud, 7(1),179-208.
Castro, L.R.; Correa, J. (2005). Mostrando a real: um relato da juventude pobre no Rio de Janeiro. Rio de Janeiro: NAU Editora: FAPERJ.

Castro, M.G.; Abramoway, M. (2009). Quebrando Mitos - juventude, participação e políticas: perfil, percepções e recomendações dos participantes da $1^{\text {a }}$ Conferência Nacional de Políticas Públicas de Juventude. Brasília: RITLA.

Calil Stamato, M.I. (2008). Protagonismo Juvenil: uma práxis sócio histórica de ressignificação da juventude. Tese (Doutorado em Psicologia Social). Pontifícia Universidade Católica de São Paulo - PUC-SP. São Paulo.

Dayrell, J. (2010). Juventudes. In: Revista Presença Pedagógica, 16 (93), 60-66.

D'angelo, H.O. (1994). Modelo integrativo del proyecto de vida. Habana: Provida.

Groppo, L.A. (2000). Juventude: ensaios sobre a sociologia e história das juventudes modernas. Rio de Janeiro: DIFEL.

Leff, E. (2002). Agroecologia e saber ambiental. In: Agroecologia e Desenvolvimento Rural Sustentável. Porto Alegre: EMATER/RS, 3 (1).

Loreto, M.D.S.; Miranda, E.L.; Gonçalves, A. (2018). Reflexões sobre o significado de ser jovem no meio rural brasileiro. In: X Congresso Alasru, (1-20), Montevideo.

Manhani, D. C. (2000). Uma avaliação do programa de formação de jovens empresários rurais: Projovem. Dissertação (Mestrado em Economia Aplicada), Escola Superior de Agricultura Luiz de Queiroz, Universidade de São Paulo, Piracicaba.

Medrado, M.J.S. (2000). Sistemas agroflorestais: aspectos básicos e indicações. In: GALVÃO, A. P. M. (Org.). Reflorestamento de propriedades rurais para fins produtivos e ambientais: um guia para ações municipais e regionais. Brasilia: Embrapa Comunicação para Transferência de Tecnologias; Colombo, PR: Embrapa Floresta.

Melucci, A. (1997). Juventude, tempo e movimentos sociais. Revista Brasileira de Educação/ANPEd, 5(6), 5-14.

Novaes, R. (2005). Juventude, percepções e comportamentos: a religião faz a diferença? In: Abramo, Helena; Branco, Pedro Paulo Martoni. Retratos da Juventude Brasileira: análises de uma pesquisa nacional. São Paulo: Instituto Cidadania/Editora Fundação Perseu Abramo. 
Pereira, J.L. (2004). Juventude rural: para além das fronteiras entre o campo e a cidade. Tese (Doutorado em Antropologia Social). Programa de Pós-Graduação em Sociedade e Agricultura. Instituto de Ciências Humanas e Sociais-UFRRJ, Rio de Janeiro.

Piancentini, P. (2016) Juventude e trabalho no campo: permanência dos jovens no meio rural depende da geração de oportunidades além do trabalho na terra. Revista Pré Univesp, 21(3), 10-25.

Queiroz, M.I.P. (1978) Cultura, Sociedade Rural e Sociedade Urbana no Brasil. São Paulo: Edusp.

Ramos, V. S.; Angnes, J.; Costa, Z. (2018). O Futuro da Fumicultura: O Jovem Rural e o Dilema da Sucessão Geracional. Desenvolvimento em Questão, 16 (43), 548-572.

Redin, E. (2012). Jovem rural em questão. Revista Sociais e Humanas, Santa Maria, 25 (1), 123-139.

Santori, R. (2008). A juventude rural e suas perspectivas. Revista da Formação por Alternância UNEFAB, Brasília, 4 (7), 05-16.

Silva. J.G. (1998). Agricultura Sustentável: um novo paradigma ou um novo movimento social? In: Almeida, J., Navarro, Z. Reconstruindo a agricultura: Idéias e idéias na perspectiva do desenvolvimento rural sustentável. $\quad 2^{\mathrm{a}} \quad \mathrm{Ed}$. Porto Alegre: Ed. Universidade/UFRGS.

Souza-lobo, E. (1991). A classe operária tem dois sexos; trabalho, dominação e resistência. São Paulo, Brasiliense.

Troian, A. (2014). Percepções e projetos de jovens rurais produtores de tabaco de Arroio do Tigre/RS. 2014. Tese (Doutorado em Desenvolvimento Rural) Universidade Federal do Rio Grande do Sul (UFRGS), Porto Alegre.

Velho, G. (1994). Memória, identidade e Projeto. In: Projeto e metamorfose: Antropologia das sociedades complexas. Rio de Janeiro: Jorge Zahar Ed.

Velho, G. (1999). Individualismo e cultura. Notas para uma Antropologia da Sociedade Contemporânea. Rio de Janeiro: Jorge Zahar Ed.

Wanderley, M. N.B. (2000). A emergência de uma nova ruralidade nas sociedades modernas avançadas: 0 rural como espaço singular e ator coletivo. Recife, Universidade Federal de Pernambuco, (mimeografado).

Wanderley, M. N. B. (2007). Jovens rurais de pequenos municípios de Pernambuco: que sonhos para o futuro.
In: Carneiro, Maria José \& Castro, Elisa Guaraná de (org.). Juventude rural em perspectiva. Rio de Janeiro: Mauad X.

Weisheimer, N. (2009). A situação juvenil na agricultura familiar. Tese de doutorado em Sociologia. UFRGS. 